\title{
Individual Patient Data Meta-Analysis of the Smoking Prevalence in Mazandaran Province of Iran
}

\author{
Mahmood Moosazadeh ${ }^{1}$; Mohammadreza Amiresmaili ${ }^{2}$; Mahdi Afshari ${ }^{3,}$ \\ ${ }^{1}$ Health Sciences Research Center, Mazandaran University of Medical Sciences, Sari, IR Iran \\ ${ }_{2}^{2}$ Research Center for Health Services Management, Institute of Futures Studies in Health, Kerman University of Medical Sciences, Kerman, IR Iran \\ ${ }^{3}$ Department of Community Medicine, Zabol University of Medical Sciences, Zabol, IR Iran \\ ${ }^{*}$ Corresponding Author: Mahdi Afshari, Department of Community Medicine, Zabol University of Medical Sciences, Zabol, IR Iran. Tel: +989155420552, E-mail: E-mail: mehdiaf- \\ shari16@yahoo.com
}

Received: January 15, 2013; Revised: November 21, 2013; Accepted: November 12, 2014

\begin{abstract}
Background: Smoking is regarded as one of the main risk factors and additive to the global burden of diseases in the World.
Objectives: This individual patient data (IPD) meta-analysis aimed to estimate the smoking prevalence in Mazandaran province of Iran.

Materials and Methods: This study was an IPD meta-analysis. The study data were part of the STEPS Study in Mazandaran province (northern Iran), conducted annually from 2005 to 2009. Sample size was 7759 subjects. Sampling method was census. Data entry was in Epi6 software and the analyses were with stata 11 software.

Results: Mean (standard error) age of starting to smoke was 20.21 (0.6) years and females had started smoking 4 years later $(\mathrm{P}=0.01)$. During the study, men smoked cigarettes more than women (total prevalence: 23.2\%; 95\% CI: 22.5-23.9 vs. 0.9\%; 95\% CI: 0.7-1.1 respectively). The pooled prevalence of the current smoking was estimated about $12.08 \%$ (95\% CI:11.40-12.81).

Conclusions: Present study showed that the prevalence of Smoking in men is very high in this region of Iran. Therefore to prevent the problem it is necessary that educational and research centres and health providers make suitable policies and strategies .
\end{abstract}

Keywords:Smoking; Cigarette; Iran; Prevalence

\section{Background}

Smoking is regarded as one of main risk factors and additive to global burden of disease particulary from chronic and non-communicable diseases such as cardiovascular and respiratory diseases as well as stroke. Smoking can lead to cancer of mouth, throat, lung, larynx, bladder, esophagus, kidney, pancreas, cervical and liver additionally, it is the leading cause of preventable mortality worldwide (1-4). Doll et al. in a fifty-year study concluded that smokers live ten years less than nonsmokers (5). Scientific research also indicates that smoking is not only harmful for smokers but also for other people around them (6). WHO estimates that death caused by smoking will decrease 9 percent in developed countries during 2002-2030 however this figure will double in developing countries (7). Also, based on WHO reports, three million deaths has happened annually in 1990s, of which 2 million have happened in developed countries, but it is predicted that in 2020 s and early 2030s, ten million deaths will happen, of which 3 million and 7 million will be from developed and developing countries respectively. According to this report, every ten seconds one death of smoking happens, which will reach to one death in every three seconds in next 30-49 years $(4,7)$. Based on one of the most recent studies, 14 percent of iranian populations are tobacco consumers and male smokers are 6 times more than females. In this study which has reported smoking prevalence in different provinces of Iran, Ilam (7.6\%), Yazd (8.6\%) and Golestan (9.1\%) are categorized in the lowest decile wheras Sistan va Baluchestan (20.3\%) and Bushehr (21.2\%) are placed in the highest decile of smoking prevalence (8). Also according to another WHO reprt, burden of tobacco related diseases is increasing in developing countries including Iran (9). Considering the conflicts present in individual studies, we aimed to determine smoking pattern in different age, gender, residence area, and job categories, in an individual patient data meta anlysis drawing on five years data bank of national Surveillance of Risk Factors of Non-Communicable Diseases (SuRFNCD) Because, Conventional systematic reviews and meta-analyses rely on aggregated information. Since there is usually no access to data other than those reported by the original authors, the meta-analyses are restricted by the analyses performed in the original studies and some errors such as aggregate biase can distort results (10). On the other hand, IPD meta-analysis is suggested as the least biased method of addressing questions that cannot be resolved by a single study. Including data from a few high-quality longitudinal studies might provide more detailed and reliable conclusions than analysis of a larger number of disparate aggregated

Copyright ( 2015, Iranian Red Crescent Medical Journal. This is an open-access article distributed under the terms of the Creative Commons Attribution-NonCommercial 4.0 International License (http://creativecommons.org/licenses/by-nc/4.0/) which permits copy and redistribute the material just in noncommercial usages, provided the original work is properly cited. 
studies (11). IPD meta-analysis can provide greater clarity than a meta-analysis based on aggregated published data because the raw data from individual studies can be re-categorized to apply more consistent definitions. This is particularly useful for meta-analysis of observational epidemiological studies, including those investigating the prevalence of smoking, because multivariable analyses can be performed using a consistent set of factors that might cause confounding or effect modification (10, 11). Such analyses of individual data are generally more statistically efficient than those based on published aggregated data. Analyses of individual patient data can overcome some of the limitations of publication and reporting biases and short duration of follow up if more recent data from ongoing studies can be analyzed. With IPD, the effects of exposures in population subgroups can also be analysed more flexibly than with aggregated data.

\section{Objectives}

The aim of this study was to the determine the prevalence of smoking using IPD meta-analysis.

\section{Materials and Methods}

Data sources and Data collection: The data of this study was part of the STEPS Study in Mazandaran (northern Iran) which was conducted annually during 2005-2009. This survey was approved by the ethics committee of the Center for Disease Management of Iran. All information was collected using a standardized universal questionnaire (12) which contained general, demographic, anthropometric, behavioral and clinical information of 15-64 year old people ( 5 age groups with 10 year interval) living in urban and rural areas of Mazandaren province. The tobacco-related questions of the Stepwise Approach to Chronic Disease Risk Factor Surveillance are built according to WHO guidelines for tobacco use surveillance documents. In brief, respondents were asked about current and daily use of any amount of any tobacco products including cigarettes, cigars, pipes and water-pipes. Current cigarette smoking was defined as smoking any amount of any kind of factory or hand-made cigarettes, or cigars at the time of the interview. The 'current cigarette smokers' who smoked daily, were defined as 'daily cigarette smokers'. Study sample was selected using one stage cluster sampling method in which postal areas (cities) or households (villages) considered as primary sampling units. Based on the National STEPS Project, the relevant estimated sample size in each year was 1000 except for 2005 which was 3759 subjects. To ensure quality of data collection ninety four teams consisting of two trained interviewers collected data from study sample and 30 supervisors was selected for quality control of the study. Method sampling, In the steps study, was cluster and stratified but in the present study was census because of the analysis of all samples of studied in the steps. This study was done in coordination with health deputy of mazandaran university of medical sciences. Additionally, analysis was carried out without the name of participant in the study. All data was entered in to EPI6 software.

\subsection{Statistical analysis}

All data were analyzed separately and totally (by merging the 5 years data). Annual results were compared and the trends of the indicators were investigated. Descriptive statistics were conducted using mean (standard error) and percent frequency. Mean of indicators in different sex, age groups, jobs and residency areas were compared using independent t-test and the prevalence were compared using chi square test. P value of less than 0.05 was considered as significant level. In addition, a meta-analysis for estimating the pool weighted prevalence of obesity of the 5 years results was carried out considering the degree of heterogeneity of the results (Q). All estimates were directly standardized based on real population size of different age-sex groups of Mazandaran province in national census 2006 to reduce the biases due to equal sizes of age and sex groups in the study sample. Analyses were performed using stat ver. 11 .

\section{Results}

Totally 7759 subjects were recruited in this study with the participation rate of $100 \%$, most of which (3759) were in 2005. The average age of the participants was 39.49, proportion of males and females and mean of age in both genders differences were not statistically significant $(\mathrm{P}=$ 0.9). Total standardized prevalence of cigarette smoking was $12.2 \%$ ( 11.4-12.9) which significantly differed between males and females in all years of the study $(\mathrm{P}<0.0001)$, different age groups $(\mathrm{P}<0.0001)$ and jobs $(\mathrm{P}<0.0001)$. Except for $2006(\mathrm{P}=0.03)$, no statistically significant difference between rural and urban residents was observed $(P=0.5)$ (Table 1). Also, During all years of the study, males smoked cigarette more than females (total prevalence: 23.2\%; 95\% CI: $22.5-23.9$ vs. 0.9\%; 95\% CI: 0.7-1.1). According to Table 2, 35 to 44 years-old subjects (both males and females) had smoked cigarette more than the other age groups (19.6\%; 95\% CI:19.2-19.9) and only youngest males had prevalence less than 10\% (4.6\%; 95\% CI: 4.3-5) while in women aged 25-34 and 45-54 this prevalence was lower than others. Among the different job groups during all 5 years of the study, retired people and house-wives had the highest and the least prevalence of smoking respectively (41.2\%; 95\% CI: 38.2-44.2 and 1.6\%; 95\% CI: 0.5-4.9 respectively). Prevalence of smoking had a significant decrease during these 5 years among retired people from $41.2 \%$ (37.7-44.9) to 13.9\% (12.5-15.4) (Table 1). Mean (standard error) age of starting to smoke was 20.21 (0.6) and females had started smoking 4 years later $(P=0.01)$. Only in age group of 25-34, the starting age of females was earlier than males $(\mathrm{P}<0.0001)$ (Table 2$)$. This mean age in 2006 was more than the other times (22.19 years; $\mathrm{SE}=0.87$ ) which decreased to about 18 years in the latter years (Figure 1). About $85 \%$ of participants started smoking before age 25 
and only $4 \%$ started after 35 . On average, about 10.32 cigarettes per day were smoked during the study period with no statistically significant difference according to gender ( $P=0.1$ ) except for 35-44 and 45-54 year-old subjects whose mean number of cigarettes in men was significantly higher than women $(\mathrm{P}=0.05$ and $\mathrm{P}=0.03$ respectively) (Table 2). People aged 15-24 smoked 6.6 cigarettes per day while participants aged 45-64 smoked the highest number of cigarettes per day (12.8). This average number of cigarettes differed from $10.11(\mathrm{SE}=0.99)$ in 2006 to $13.13(\mathrm{SE}=0.63)$ in 2009 (Figure 1). In The meta-analysis of the 5 years results, using fixed model with no heterogeneity of results $(\mathrm{Q}=$ $5.95, P=0.2)$, the pooled prevalence of current smoking was estimated about $12.08 \%$ (95\% CI: 11.40-12.81) (Figure 2).

Table 1. Annual and Total (IPD Meta-Analytic) Prevalence of Current Smoking in Relation to Demographic and Socioeconomic Status of the Study Subjects

\begin{tabular}{|c|c|c|c|c|c|c|}
\hline Variables & 2005 & 2006 & 2007 & 2008 & 2009 & Total \\
\hline \multicolumn{7}{|l|}{ Sex } \\
\hline Male & $23.9(22.8-25)$ & $24.8(22.8-26.2)$ & $21.1(19.5-23)$ & $21(19.3-22.9)$ & $23(21.4-24.5)$ & $23.2(22.5-23.9)$ \\
\hline Female & $1.1(0.9-1.4)$ & $1.5(0.9-2.3)$ & $0.7(0.4-1.1)$ & $0.2(0.1-0.4)$ & $0.2(0.1-0.7)$ & $0.9(0.7-1.1)$ \\
\hline Total P value & & & & & & $<0.0001$ \\
\hline \multicolumn{7}{|l|}{ Residence area } \\
\hline Urban & $12.7(11.1-14.5)$ & $10.9(8.1-14.5)$ & $9.3(6.7-12.7)$ & $12.4(9.9-15.3)$ & $10.1(8-12.8)$ & $11.8(10.7-13)$ \\
\hline Rural & $12.6(10.9-14.4)$ & $15.6(13.3-18.4)$ & $12(10.1-14.3)$ & $9.7(7.6-12.3)$ & $12.7(10.8-15)$ & $12.5(11.5-13.5)$ \\
\hline Total P value & & & & & & 0.5 \\
\hline \multicolumn{7}{|l|}{ Age group } \\
\hline $15-24$ & $7.7(6.7-8.8)$ & $9.9(8.5-11.5)$ & 11.5 (9.4-13.9) & $8.2(6.5-10.2)$ & $6(4.6-7.7)$ & $4.6(4.3-5)$ \\
\hline $25-34$ & $28.8(27.6-30.2)$ & $33(30.3-35.8)$ & $18.4(16.4-20.5)$ & $26.5(24.3-28.9)$ & $30(28.5-31.6)$ & $14.5(14.1-15)$ \\
\hline $35-44$ & $40.5(39.6-41.4)$ & $33(31.6-34.4)$ & $31.9(30-33.9)$ & $34(32.3-35.8)$ & $36.4(34.5-38.3)$ & $19.6(19.2-19.9)$ \\
\hline $45-54$ & $34.6(34-35.2)$ & $36.5(35.3-37.7)$ & $34.3(33.2-35.4)$ & $26.6(25.5-27.7)$ & $34(32.5-35.6)$ & $17.4(17.2-17.6)$ \\
\hline $55-64$ & $25(24.7-25.3)$ & $28(27.3-28.7)$ & $30.8(30.3-31.4)$ & $22.1(21.7-22.6)$ & $28.7(28.3-29.2)$ & $13.5(13.4-13.6)$ \\
\hline Total P value & & & & & & $<0.0001$ \\
\hline \multicolumn{7}{|l|}{ Job } \\
\hline Clerk & $13.4(11.8-15.2)$ & $13.7(10.8-17.2)$ & $12.7(10.2-15.8)$ & $11.1(8.6-14.2)$ & $12.3(9.6-15.5)$ & $13.1(12-14.3)$ \\
\hline Student/ soldier & $5.5(2.4-11.8)$ & $7.6(2.9-18.4)$ & $10.6(5.4-19.6)$ & $4.7(1.9-10.8)$ & $1.7(0.9-3.3)$ & $4.4(2.5-7.6)$ \\
\hline House work & $0.5(0.2-1.1)$ & $2.1(1.2-3.8)$ & $0.8(0.5-1.3)$ & $5.1(5.1-5.2)$ & 0 & $1.6(0.5-4.9)$ \\
\hline Retired & $41.2(37.7-44.9)$ & $17.1(15.6-18.7)$ & $11(9.5-12.7)$ & $35.9(32.4-39.5)$ & $13.9(12.5-15.4)$ & $41.2(38.2-44.2)$ \\
\hline Other & $16.2(12.9-20.1)$ & $22.4(18.1-27.5)$ & $10.2(6.5-15)$ & $14.2(9.4-21)$ & $12.9(9.8-16.8)$ & $15.1(13.1-17.3)$ \\
\hline Total P value & & & & & & $<0.0001$ \\
\hline Total & $12.6(11.5-13.9)$ & $13.3(11.5-15.2)$ & $11.1(9.5-13)$ & $10.7(9.1-12.7)$ & $11.7(10.2-13.4)$ & $12.2(11.4-12.9)$ \\
\hline
\end{tabular}

\begin{tabular}{|c|c|c|c|c|c|c|c|}
\hline Variable & 15-24 & $25-34$ & $35-44$ & $45-54$ & $55-64$ & Total & Total \\
\hline \multicolumn{8}{|c|}{$\begin{array}{l}\text { Prevalence of cur- } \\
\text { rent smoking, CI }\end{array}$} \\
\hline Male & $8.3(7.6-9.6)$ & $27.9(27-28.8)$ & $37.1(36.5-37.8)$ & $33.7(33.3-34.2)$ & $26.2(26-26.4)$ & $23.2(21.8-24.6)$ & $12.2(11.4-12.9)$ \\
\hline Female & $0.9(0.7-1.2)$ & $0.6(0.5-0.8)$ & $1.3(1.1-1.5)$ & $0.6(0.6-0.7)$ & $1.1(1.1-1.2)$ & $0.9(0.6-1.3)$ & \\
\hline PValue & $<0.0001$ & $<0.0001$ & $<0.0001$ & $<0.0001$ & $<0.0001$ & $<0.0001$ & \\
\hline $\begin{array}{l}\text { Age of smoking } \\
\text { started }\end{array}$ & & & & & & & $20.21 \pm 0.6$ \\
\hline Male & $15.89 \pm 0.7$ & $19.19 \pm 0.4$ & $19.52 \pm 0.6$ & $21.73 \pm 0.7$ & $22.73 \pm 0.9$ & $18.62 \pm 0.3$ & \\
\hline Female & 0 & $16.5 \pm 0.3$ & $30.5 \pm 4.6$ & $22 \pm 0$ & $27.25 \pm 7.9$ & $22.8 \pm 1.6$ & \\
\hline PValue & - & $<0.0001$ & 0.02 & 0.7 & 0.6 & 0.01 & \\
\hline $\begin{array}{l}\text { Number of daily } \\
\text { cigarettes }\end{array}$ & & & & & & & $10.32 \pm 1$ \\
\hline Male & $8.25 \pm 1.03$ & $10.86 \pm 0.5$ & $14.72 \pm 0.5$ & $16.42 \pm 0.6$ & $14.61 \pm 0.7$ & $11.59 \pm 0.4$ & \\
\hline Female & $(5 \pm 3.54)$ & $(14 \pm 4.9)$ & $(9.22 \pm 2.7)$ & $(9 \pm 2.3)$ & $(11 \pm 2.8)$ & $9.03 \pm 1.9$ & \\
\hline P Value & 0.4 & 0.5 & 0.05 & 0.003 & 0.2 & 0.1 & \\
\hline
\end{tabular}


Moosazadeh Met al.

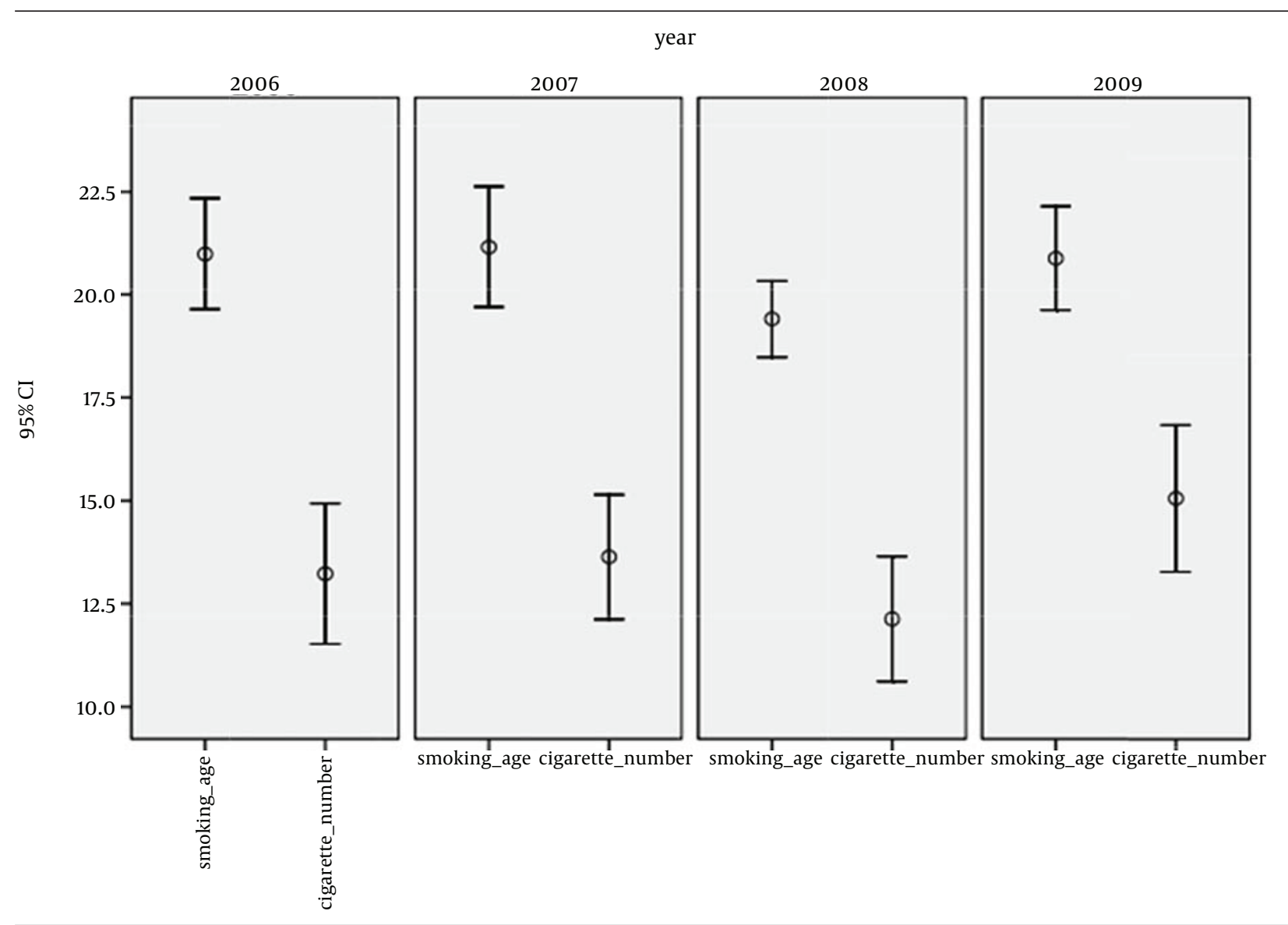

Figure 1. Mean and 95\% Confidence Interval of Age Start Smoking and Number of Cigarette Per Day (Mazandaran STEPS Study; 2005-2009)

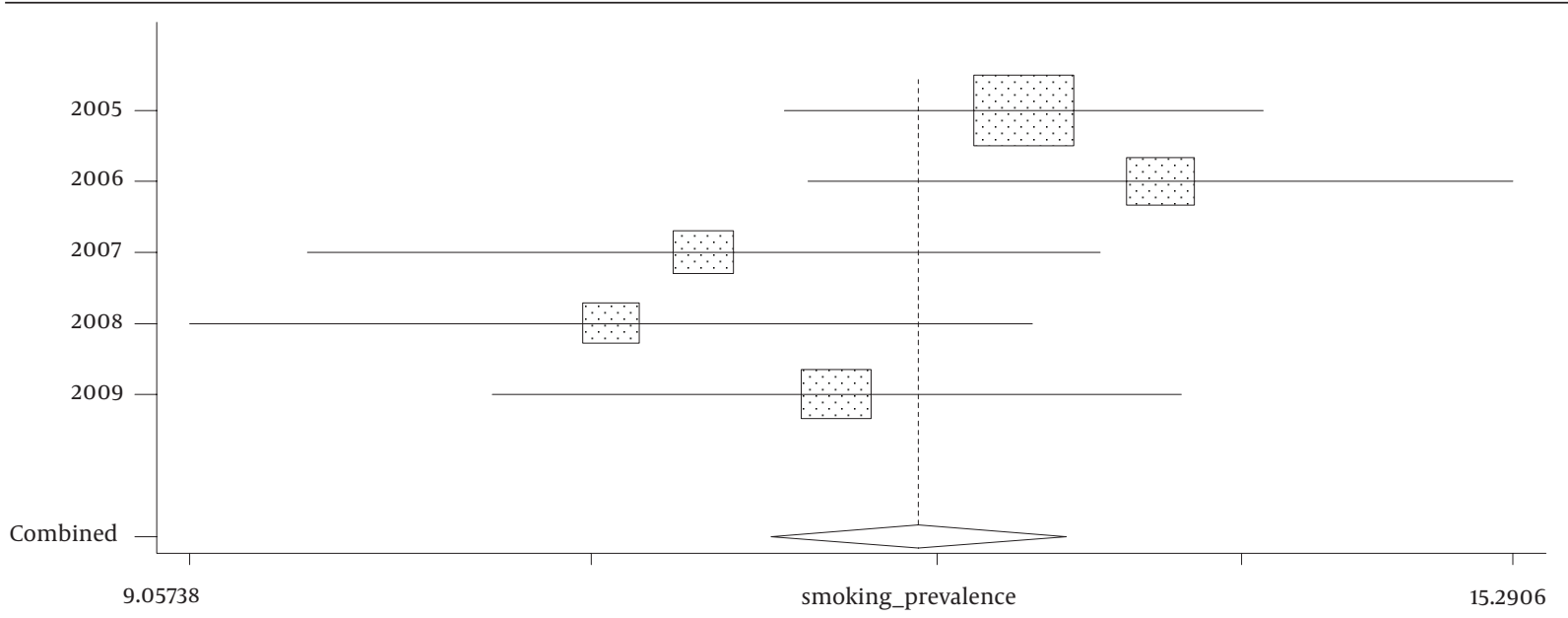

Figure 2. Forest Plot for Meta- Analysis of Prevalence of Current Smoking (Mazandaran STEPS Study, 2005-2009)

\section{Discussion}

Our study showed that the prevalence of current smoking and mean number of cigarettes smoked per day in north of Iran was $12.2 \%$ and 10.32 respectively, with the higher prevalence in men, middle age groups and retired people and mean age of start more than 20 years. The observed prevalence of current smoking in this region was similar to the average prevalence of Iran (13) and the results of studies in southern (14),eastern (15) and middle 
(16-18) parts of Iran. But was lower than that of western of Iran (13). It also was slightly lower than the rates of other countries of the region such as Kuwait (17\%) (19), Turkey (13\%) (20) and most of eastern Mediterranean Countries (21). It should be noted that social, cultural and religious factors might be the main cause for this lower rate and also establishing and good obey from the restricting rules about cigarette smoking in the country particularly in the northern part of Iran should be taken into account. Similar to the results of the current study, in all other studies, men smoked more than women (13-15, 18, $19,21)$ and the number of consumed cigarettes in most of them was higher in men $(18,19)$ in contrast to our study in which no significant difference between genders was observed, Moghimbeigi et al. showed that gender of female increased the chance of "not to smoke cigarette at all" (22). Lower rates of smoking could partially be due to sociocultural factors lead to under reporting of smoking. Women especially in Iran and many developing countries tend to hide their smoking habits to avoid social stigmatization (17), and in such regions it may be considered abnormal for females to be seen smoking in public (19). We found that the prevalence of current smoking in the middle aged participants of both genders was more than that of the other age groups. That was similar to the results of the national Survey of" Risk Factors of Non-Communicable Diseases in Iran (SuRFNCD-2007)", but in contrast to the findings of similar studies in specific parts of Iran (14, 15,18 ) that reported more prevalence of current smoking in older people and also the results of another population based study in Kuwait indicated that smoking was more prevalent in younger men and older women (19). In our study, smokers on average, started smoking in the age of 20.21 which was in accordance with the mean age of starting smoking in Iran (13) and Kuwait (19) and was higher than the other countries in the region whose people started smoking in the age of 15 (21). Moreover, in all of these studies, women start cigarette smoking later than men. The majority of participants in the current study started smoking before the age of 25 . Moreover, according to the results of some studies, the number of attempts to quit smoking in Iran is lower compared to the some other countries (17). It seems that people in this area of Iran, smoked lower number of cigarettes per day [10.3] compare to the average number of Iran (13), Hormozgan (southern province of Iran) (14) and Kuwait (19) and unlike these regions, In our study, men smoked cigarettes as much as women. We also found more smokers in retired people while Ayyagari et al. showed that job stress is positively related to continuing to smoke and to the number of cigarettes smoked for current smokers (23). But lower prevalence of smoking in housewives could be due to the fact that this group is consisted only from women and low prevalence of smoking among women. One of the strengths of the study was using IPD meta-analysis method, Because IPD meta-analyses can improve the quality of data and the type of analyses that can be done and pro- duces more reliable results. For this reason they are considered to be a gold standard of systematic review. One of the most weaknesses and limitations of the current study was the potential biases due to poor recall in participants and probable under reporting because this behavior is considered as an unfavorable practice particularly among women and it is believed that this under reporting may be higher in Iran than many other countries due to conservative Iranian society (16). Therefore, real prevalence especially in women might be higher than that reported in the present study. In conclusion, although the prevalence of current smoking in northern part of Iran is not considerable compared to the other regions, but unfavorable impacts of this habit in the community makes us responsible for implementation of suitable preventive efforts especially in younger age groups.

\section{Acknowledgements}

The authors thanks to everyone who made it possible to conduct the present study specially research teams who collected data, expert in charge of health of Mazandaran University of Medical Sciences.

\section{Authors' Contributions}

Mahmood Moosazadeh and Mahdi Afshari participated in Data cleaning and analysis, also both of them contributed to Writing of the manuscript. Mohammadreza Amiresmaili contributed in manuscript preparation.

\section{References}

1. Haenle MM, Brockmann SO, Kron M, Bertling U, Mason RA, Steinbach G, et al. Overweight, physical activity, tobacco and alcohol consumption in a cross-sectional random sample of German adults. BMC Public Health. 2006;6:233.

2. Oliveira A, Barros H, Maciel MJ, Lopes C. Tobacco smoking and acute myocardial infarction in young adults: a population-based case-control study. Prev Med.2007;44(4):311-6.

3. Ezzati M, Henley SJ, Thun MJ, Lopez AD. Role of smoking in global and regional cardiovascular mortality. Circulation. 2005;112(4):489-97.

4. Haghdoost AA, Moosazadeh M. The prevalence of cigarette smoking among students of Iran's universities: A systematic review and meta-analysis. J Res Med Sci. 2013;18(8):717-25.

5. Doll R, Peto R, Boreham J, Sutherland I. Mortality in relation to smoking: 50 years' observations on male British doctors. BMJ. 2004;328(7455):1519.

6. Jamrozik K. Estimate of deaths attributable to passive smoking among UK adults: database analysis. BMJ. 2005;330(7495):812.

7. Mathers CD, Loncar D. Projections of global mortality and burden of disease from 2002 to 2030. PLoS Med. 2006;3(11).

8. Jamshidi Ardeshiri M, Moosazadeh M, Feizi Masouleh M, Feizi Masouleh M, Kiani A, Fakhri M. Prevalence of smoking in 15-64 years old population of north of Iran: meta-analysis of the results of non-communicable diseases risk factors surveillance system. Acta Med Iran. 2013;51(7):494-500.

9. World Health Organization. WHO report on the global tobacco epidemic: the MPOWER package. Geneva: WHO; 2008. Available from: http://www.who.int/tobacco/mpower/mpower_report_full _2008.pdf.

10. Riley RD, Simmonds MC, Look MP. Evidence synthesis combining individual patient data and aggregate data: a systematic review identified current practice and possible methods. J Clin Epidemiol. 2007;60(5):431-9. 


\section{Moosazadeh Met al.}

11. Stewart LA, Tierney JF. To IPD or not to IPD? Advantages and disadvantages of systematic reviews using individual patient data. Eval Health Prof. 2002;25(1):76-97.

12. Moosazadeh M. Meta-Analysis of Prevalence of Smoking in 15-64-year-old Population of West of Iran. Int J Prev Med. 2013;4(10):1108-14.

13. Meysamie A, Ghaletaki R, Haghazali M, Asgari F, Rashidi A, Khalilzadeh O, et al. Pattern of tobacco use among the Iranian adult population: results of the national Survey of Risk Factors of Non-Communicable Diseases (SuRFNCD-2007). Tob Control. 2010;19(2):125-8.

14. Aghamollaei T, Zare S. Cigarette consumption in the population over 15 years of Bandar Abbas: a population-based study. J Hormozghan Med. 2007;11(4):241-6.

15. Boskabady MH, Mahmoudinia M, Eslamizade MJ, Boskabady M, Shakeri MT, Heydari GR. The prevalence of smoking among the population in the city of Mashhad (north east of Iran) and pulmonary function tests among smokers. Pneumonol Alergol Pol. 2011;79(1):21-5.

16. Sarraf-Zadegan N, Boshtam M, Shahrokhi S, Naderi GA, Asgary S, Shahparian M, et al. Tobacco use among Iranian men, women and adolescents. Eur J Public Health. 2004;14(1):76-8.

17. Eftekhar Ardebili M, Nassr M, Rassulian M, Ghalebandi MF, Dane- shamuz B, Salehi M. Prevalence of Cigarette Smoking in Tehran: A household study. Iran J Psychiatry Behav Sci. 2007;1(2):33-7.

18. Fotouhi A, Khabazkhoob M, Hashemi H, Mohammad K. The prevalence of cigarette smoking in residents of Tehran. Arch Iran Med. 2009;12(4):358-64.

19. Memon A, Moody PM, Sugathan TN, el-Gerges N, al-Bustan M, alShatti A, et al. Epidemiology of smoking among Kuwaiti adults: prevalence, characteristics, and attitudes. Bull World Health Organ. 2000;78(11):1306-15.

20. Yazici H. The Relationship Between the Turkish Adolescents' Smoking and Their Family Environment. World Appl Sci J. 2008;4(4):600-4.

21. Tessier JF, Nejjari C, Bennani-Othmani M. Smoking in Mediterranean countries: Europe, North Africa and the Middle-East. Results from a co-operative study. Int J Tuberc Lung Dis. 1999; 3(10):927-37.

22. Moghimbeigi A, Eshraghian MR, Mohammad K, Nourijelyani K, Husseini M. Determinants number of cigarette smoked with Iranian adolescents: A multilevel zero inflated poisson regression model. Iran J Public Health. 2009;38(4):91-6.

23. Ayyagari P, Sindelar JL. The Impact of Job Stress on Smoking and Quitting: Evidence from the HRS. B EJ Econom Anal Policy. 2010;10(1). 